\title{
CONTRATUALISMO, UTILITARISMO E PLURALISMO NA TEORIA DA JUSTIÇA DE RAWLS
}

\author{
CONTRACTUALISM, UTILITARIANISM AND PLURALISM IN \\ RAWLS'S THEORY OF JUSTICE
}

\author{
DELMO MATTOS ${ }^{1}$ \\ (Universidade CEUMA, FAPEMA, Brasil)
}

\begin{abstract}
RESUMO
O propósito fundamental desse artigo consiste em um exame do argumento contratualista de Rawls, tal como se apresenta na sua obra Teoria da Justiça. Com base nesse pressuposto, as discussões pretendem evidenciar o modo pelo qual o procedimento contratualista permite ao filósofo contrapor os princípios do utilitarismo no que concerne a justificação da justiça. Sendo assim, torna-se fundamental um exame acerca do modelo de justiça proposto pelo utilitarismo, a fim de demonstrar a incompatibilidade teórica entre o princípio da utilidade e a concepção da cooperação social. Para tanto, demonstra-se que a fundamentação da justiça empreendida por Rawls é inseparável da utilização instrumental de um acordo cerca dos arranjos adequados ao bem da sociedade, cujos princípios constituem a justiça social. Diante desses elementos teóricos, evidencia-se a relação efetiva entre o contratualismo e o pluralismo através do qual serão extraídos os princípios determinantes do modelo de sociedade organizada sob as determinações da cooperação social. Por fim, demonstra-se, mediante os argumentos apresentados, uma objeção às afirmativas costumeiras e relações infundadas sobre a proposta contratualista como fundamento dos princípios da justiça.
\end{abstract}

Palavras-chave: Contratualismo. Equidade. Utilitarismo. Pluralismo. Multiculturalismo.

\begin{abstract}
The fundamental purpose of this article consists of an examination of the contractarian Rawlsian argument, as presented in his Theory of Justice. On that basis, the discussions aim to highlight the way in which the contractarian procedure allows the philosopher to oppose the principles of utilitarianism concerning the justification of justice. Thus, it becomes essential to an examination about the justice model proposed by utilitarianism to demonstrate the theoretical incompatibility between the principle of utility conception of social cooperation. For both, it is demonstrated that the reasoning of justice undertaken by Rawls is inseparable from the instrumental use of an agreement about the appropriate arrangements to good society, whose principles are social justice. Given these theoretical elements, highlights the effective relationship between contractarianism and pluralism through which will be extracted from the determinants of company organized under the provisions of social cooperation model principles. Finally, it is demonstrated by the arguments presented an objection to customary affirmative and unsubstantiated relationships on contractualist proposal as the basis of the principles of justice.
\end{abstract}

Keywords: Contractualism. Fairness. Utilitarianism. Pluralism. Multiculturalism.

\section{Introdução}


Conforme evidencia Miller (1975, p. 57), a própria expressão que ambiciona definir o cerne da teoria da justiça proposta por Rawls, ou seja, "a justiça com equidade (a justice as fairness) deixa subentendido que a escolha de determinados princípios de justiça requer necessariamente um viés consensual" ${ }^{\prime 2}$. Diante dessa afirmativa, torna-se possível compreender que as discussões acerca da justiça, tal como é proposta pelo filósofo estadunidense explicita, através da figura do contrato, a necessidade de que os princípios da justiça sejam decorrentes, e não exclusivamente, de um acordo consensual. Por sua vez, essa justificativa tem como pressuposto oferecer uma alternativa aos preceitos e princípios fundamentais da argumentação utilitarista. Trata-se de fundamentar uma perspectiva que possa efetivamente garantir e justificar os direitos e deveres assegurados pelas sociedades democráticas aos seus respectivos cidadãos, assim como assegurar a liberdade de crença e de opinião, na afirmação da livre discussão pública e na defesa da integridade física e psicológica de todos os cidadãos.

Partindo desse princípio, Rawls enseja a sua crítica aos anseios do utilitarismo relacionando ao fato de que, para tal argumentação, os seus respectivos critérios de justificação estariam baseados impreterivelmente na "maximização do bem-estar coletivo" em detrimento aos direitos individuais gerando, por conseguinte, uma situação de absoluta injustiça (RAWLS, 2002, p. 37). Desse modo, torna-se possível constatar que os pressupostos do utilitarismo estariam efetivamente concentrados na eficácia de uma "maximização da felicidade coletiva" sem, contudo, uma mínima preocupação com a forma pelo qual está igualmente distribuída a todos os membros da sociedade.

No argumento utilitarista, assegura Rawls (2002), para uma maior maximização da média geral de bens materiais e da segurança social torna-se legítimo o sacrifício da liberdade e de outros direitos fundamentais. Com base nessa consideração, Rawls demonstra que o princípio utilitarista considera como critério de uma sociedade bem ordenada e justa aquela no qual se priva alguns indivíduos da satisfação de seus interesses em favor da "maximização do bem-estar e satisfação da coletividade" (RAWLS, 2002, p. 34). Diante desse critério, reforça Rawls (2002, p. 193), não existe realmente nenhuma garantia de que a realização do princípio de utilidade beneficie efetivamente todos os membros da sociedade de forma igualitária, uma vez que a obtenção desse propósito requer o sacrifício das expectativas de vida das pessoas, mediante renuncia de determinados benefícios "em favor de um bem maior para todos".

Com base nesse esclarecimento fica evidente que os preceitos fundamentais do utilitarismo não satisfazem os critérios da distribuição igualitária da felicidade, o que pode ser 
explicado por serem reconhecidamente insensíveis às questões basilares de distribuição de benefícios. Desse modo, através dessa insensibilidade quanto aos aspectos da justiça, Rawls (2002) recusa veementemente a concepção de uma sociedade regida pelo principio da utilidade, ao passo que, na sua concepção, os princípios determinantes que a regem tornam-se um ingrediente absolutamente favorável à instabilidade social. Perante tal quadro teórico negativo relativo aos preceitos explicativos do utilitarismo, Rawls opta, segundo Scarre, "por aproximar-se favoravelmente aos princípios da tradição do contrato social, uma vez que pressupõe através desse expediente sobrepor o conceito de justiça como equidade à concepção utilitarista de justiça como maximização do bem-estar" (1996, p. 34).

Não obstante, a aproximação de Rawls aos princípios do argumento contratualista suscitou várias críticas, mas também profundos elogios, seja pela sua originalidade, seja por promover uma renovação teórica e da sua aplicabilidade aos termos da questão da justiça ${ }^{3}$. Trata-se, portanto, de um enquadramento teórico pelo qual o filósofo busca efetivamente evidenciar uma solução plausível para a questão da estabilidade social, decorrente da existência de múltiplas concepções do bem e crenças defendidas numa mesma sociedade democrática liberal. Na perspectiva de Rawls, segundo Danner, "a estabilidade social somente pode ser obtida através dos termos de cooperação social advinda de um acordo ou mesmo um pacto celebrado por aqueles comprometidos na efetivação da justiça como equidade em vista a identidade política dos cidadãos em uma sociedade democrática" (DANNER, 2010, p. 155).

Diante disso, Rawls propõe a resolução do problema da estabilidade, amparando-se na concepção de um acordo político, pelo qual entrecruzam-se ao que ele considera ser uma das tarefas fundamentais da filosofia política, ou seja, a sua "função prática" (SCARRE, 1996, p. 34). Tal função prática, por sua vez, exige a construção de um aparato teórico que viabilize indiscriminadamente o princípio da cooperação social e da ordem social e política cuja relevância está relacionada com os pressupostos de uma sociedade democrática que convive com o "pluralismo razoável" de concepções de bem conflitantes e incomensuráveis entre $\mathrm{si}^{4}$. Portanto, na perspectiva de Braga (2001, p. 23), "uma incursão na obtenção dessa estabilidade expõe simultaneamente a tarefa fundamental da filosofia, assim como os propósitos teóricos do modelo de contratualismo ao qual Rawls empreende e fundamenta".

Como nos esclarece Rawls (2002, p. 3-4), 
mais eficientes e bem organizadas que sejam devem ser retomadas ou abolidas se são injustas. Cada pessoa possui uma inviolabilidade fundada na justiça que nem mesmo o bem-estar da sociedade como um todo pode ignorar. Por essa razão, a justiça nega que a perda da liberdade de alguns se justifique por um bem maior partilhado por outros. Não permite que os sacrifícios impostos a uns poucos tenham menos valor que o total maior das vantagens desfrutadas por muitos. Portanto numa sociedade justa as liberdades da cidadania igual são consideradas invioláveis; os direitos assegurados pela justiça não estão sujeitos à negociação política ou ao cálculo de interesses sociais. A única coisa que nos permite aceitar uma teoria errônea é a falta de uma teoria melhor; de forma análoga, uma injustiça é tolerável somente quando é necessária para evitar uma injustiça ainda maior. Sendo virtudes primeiras das atividades humanas, a verdade e a justiça são indissociáveis.

Em diversas passagens da obra Uma Teoria da Justiça, o autor enfatiza a importância do modelo argumentativo do contrato social como a forma mais adequada de escolher princípios de justiça. Trata-se, sobretudo, de um acordo que implica inevitavelmente o pressuposto da pluralidade cultural ou do multiculturalismo no contexto das sociedades democráticas modernas caracterizadas, sobretudo, por uma "pluralidade de sujeitos" que possuem doutrinas e ideais religiosos, morais, filosóficos, políticos, morais e éticos dos mais diversos (RAWLS, 2002, p. 34). Com base nesse pressuposto, considerando que a pluralidade nada mais é do que o resultado do exercício da razão, exatamente no contexto das instituições livres da democracia, Rawls (2002) edifica uma concepção de justiça, que aplicada à estrutura básica da sociedade, resultaria no que ele concebe como sociedade bem ordenada ${ }^{5}$.

Não obstante, Rawls considera uma sociedade caracterizada como efetivamente bem ordenada "não somente quando foi planejada para promover o bem de seus membros, mas também quando é realmente regulada por uma concepção pública de justiça” (RAWLS, 2002, p. 5). Nesse caso, portanto, na sua perspectiva, a sociedade quando pretende ser justa deve, por conseguinte, ser regida por uma determinada "moralidade pública" que se caracterizada pelo reconhecimento e aceitação dos princípios de justiça por todos os membros nela envolvidos. Sendo assim, o comprometimento teórico de Rawls pressupõe certa conformidade a um modelo de justiça que se sobreponha às concepções particulares de bem sem, contudo, excluí-las efetivamente.

Na perspectiva de RAWLS (2002, p. 4-5),

Há um conflito de interesses porque as pessoas não são indiferentes no que se refere a como os benefícios maiores produzidos pela cooperação mútua são distribuídos, pois para perseguir seus fins cada um prefere uma participação maior a uma menor. Exige-se um conjunto de princípios para escolher entre várias formas de ordenação social que determinam essa divisão de vantagens e para selar um acordo sobre as partes distributivas adequadas. Esses princípios são os princípios da justiça social: eles fornecem um modo de atribuir direitos e deveres nas instituições básicas da sociedade e definem a distribuição apropriada dos benefícios e encargos da 
cooperação social.

Essa determinação, portanto, demonstra a capacidade desse modelo em satisfazer determinadas premissas consensuais, sem que haja efetivamente a interferência de uma concepção política, religiosa ou filosófica, nos termos equitativos de cooperação social, capaz de estabelecer uma concepção de justiça em uma sociedade bem organizada nos moldes do pluralismo razoável. Considerando, por conseguinte, tal condição argumentativa, a questão fundamental que se impõe acerca dessa problemática, na qual esse artigo está concernido em discutir e analisar, pode ser centralizado na indagação proferida pelo próprio Rawls (2000, p. 26), na sua obra $O$ Liberalismo Político: "como é possível existir ao longo do tempo, uma sociedade justa e estável de cidadãos livres e iguais, mas que permanecem profundamente divididos por doutrinas religiosas, filosóficas e morais razoáveis?"”

Em virtude dessa indagação, o propósito da discussão em questão privilegia um exame no qual seja absolutamente possível ressaltar os elementos constitutivos da argumentação contratualista de Rawls evidenciando, sobretudo, o modo pelo qual o seu modelo de contrato advém das suas críticas aos princípios do utilitarismo. Diante desse argumento, será possível, portanto, enfatizar a aproximação de Rawls em relação às determinações do argumento contratualista pelo qual será possível esclarecer a relação intrínseca desse argumento com o "fato do pluralismo" (FERRAZ, 2011, 145). A hipótese sustentada na discussão, que será constituída a seguir, se propõe a evidenciar que a adoção dos termos do contrato, no contexto da justiça como equidade, além de ser uma forte oposição argumentativa ao utilitarismo demonstra, consequentemente, a supressão de princípios da fundamentação da metafísica nas discussões acerca da organização da sociedade política, por uma discussão acerca da “justificação contratual dos princípios de justiça" (RAWLS, 1993, p. 54). Trata-se, portanto, de enfatizar como uma concepção política de justiça com a estrutura e o conteúdo da justiça como equidade pode ser entendida como uma concepção política e não expressamente metafísica.

Nesses termos, primeiramente analisam-se, em linhas gerais, os aspectos teóricos mais relevantes presentes na utilização dos termos do contratualismo diante da insuficiência do utilitarismo. Nesse caso, enfatizam-se os aspectos fundamentais da crítica de Rawls aos preceitos do utilitarismo. Sendo assim, torna-se preeminente examinar o argumento que se contrapõe à perspectiva do utilitarismo, que parte do propósito do bem-estar ou a felicidade da sociedade como um todo, em detrimento do bem-estar geral de cada indivíduo. Com base nisso, demonstra-se que a teoria da justiça de Rawls determina, de certa forma, um objetivo 
diferenciado do utilitarismo, ou seja, o bem-estar do indivíduo, de acordo com as suas liberdades básicas.

No segundo momento, explicita-se o modo como Rawls discute os parâmetros determinantes inseridos na sociedade contemporânea, caracterizada pela sua pluralidade. Nesse sentido, propõe-se a determinar os respectivos princípios de liberdade e da igualdade, sem que haja uma imposição de uma doutrina sobre outra. Partindo desse princípio, examinase, a partir da diferenciação entre o liberalismo político e os liberalismos abrangentes, a pressuposição de que a ideia de tolerância permanece efetivamente um desafio para as instituições políticas. Diante disso, Rawls discute a resolução do problema da estabilidade através de uma investigação no qual se estabeleça um fundamento para um acordo político como uma das tarefas fundamentais da filosofia política. Nesse sentido, demonstra-se, com base na ideia de um consenso por sobreposição, o argumento pelo qual se torna possível Rawls realizar a justificação de que a sociedade moderna, caracterizada pelo fato do pluralismo razoável, pode obter uma justificação pública razoável.

\section{A utilização dos termos do contratualismo diante da insuficiência do utilitarismo}

A sociedade, enquanto um sistema equitativo de cooperação entre os cidadãos, compreendida em sua pluralidade, ou seja, formada por pessoas portadoras de diferentes concepções filosóficas, religiosas e morais e, enquanto tal, com propósitos definidos e bem diferenciados, inicia a sua organização socialmente justa a partir do que Rawls denomina posição original (original position). Por sua vez, o caráter heurístico da concepção de posição original contém a pressuposição fundamental de que se torna absolutamente possível conceber princípios de justiça que não sejam somente uma expressão de vantagens individuais. Em relação a tais vantagens, Rawls (2002) enfatiza que o utilitarismo articula numa mesma concepção um elemento formal, a saber, o consequencialismoe também um elemento substantivo, identificando-o, por conseguinte, a uma teoria do valor baseada numa concepção de bem-estar ${ }^{6}$.

Não obstante, a concepção da ideia geral participante da teoria do valor, no qual o utilitarismo diz respeito, demonstra que as ações afetam em última instância, inevitavelmente e, de diferentes formas, o bem-estar das pessoas sujeitas efetivamente à ação. A consequência dessa proposta está relacionada ao fato de aquilo que se julga ser "bom" não condiz ao "bom em si mesmo", mas representa tão somente um meio para a promoção de um único fim: o 
bem-estar ou felicidade de todos (BEITZ, 1999, p. 12). Assim, na perspectiva utilitarista, o bem-estar ou felicidade é o que se revela intrinsecamente bom, na medida em que representa a "causa final" das ações.

Nesse sentido, Rawls (2002, p. 12) evidencia,

\begin{abstract}
Os homens devem decidir de antemão como devem regular suas reivindicações mútuas e qual deve ser a carta constitucional de fundação de sua sociedade. Como cada pessoa deve decidir com o uso da razão o que constitui o seu bem, isto é, o sistema de finalidades que, de acordo com sua razão, ela deve buscar assim um grupo de pessoas deve decidir de uma vez por todas tudo aquilo que entre elas se deve considerar justo e injusto. A escolha que homens racionais fariam nessa situação hipotética de liberdade equitativa, pressupondo por hora que esse problema de escolha tem uma solução, determina os princípios da justiça.
\end{abstract}

Conforme explicitado, na visão de Beitz (1999), nada mais coerente do que a premissa no qual a concepção de bem-estar individual defendida pelo utilitarismo possui uma propriedade agregativa que fornece sentido à ideia abstrata de bem-estar geral que, nesse caso, é concebido como um agregado ou o somatório do bem-estar de todos os afetados ou concernidos. Com base nessas considerações, no âmbito do utilitarismo, qualquer ação moralmente boa deve relacionar-se necessariamente com a promoção do bem-estar das pessoas, portanto, os agentes devem orientar-se para a maximização desse bem-estar ou, pelo menos, orientar-se com razões apropriadas para não proceder dessa forma (BEITZ, 1999, p. 12). Por sua vez, a concepção de maximização, tal como fica evidente, associa-se a um princípio de racionalidade prática que, inevitavelmente induz: se algo é bom, então é igualmente irracional a opção por um curso de ação que o promova menos diante de outra alternativa que o promova mais ${ }^{7}$.

Diante desse contexto argumentativo, Rawls (2002) ressalta para o fato de que, uma vez que as instituições decidam em favor do bem ou quando optarem por decidir entre o que é justo e o valor que o bem poderá realmente proporcionar, o critério de escolha será sempre considerado justo, conforme e somente em relação à necessidade. Nesses termos, torna-se natural inferir que a racionalidade proferida pelo utilitarismo consiste em elevar algo ao máximo e, na leitura de Rawls (2002), sob a ótica da moral, o que se deve elevar ao máximo nada mais é do que o bem.

O utilitarismo contradiz, por sua vez, o princípio liberal da legitimidade, pois na perspectiva de Rawls (2002), impõe uma concepção particular do bem como critério de justiça, enquanto o respeito pela prioridade da liberdade subentende o respeito pelo pluralismo moral e pela diversidade das concepções do bem. Nas palavras de Rawls: "A prioridade do 
justo sobre o bem revela uma concepção deontológica da justiça, ao contrário do utilitarismo, que, deriva o justo do bem através de uma concepção teleológica da justiça” (RAWLS, 2002, p. 23).

Segundo Rawls (2002), a correção das injustiças sociais só poderá advir de uma política que vise à equidade, ou seja, no senso corrente, justiça, imparcialidade. Nos termos da sua argumentação, compreende-se por equidade a retificação das desigualdades pela igualdade de oportunidades. Sendo assim, a equidade representa uma alternativa ao utilitarismo, na medida em que ela é inspirada num princípio ético fundamental, segundo o qual o outro jamais poderá ser utilizado como simples meio para atingir qualquer objetivo. Sobre essa questão Rawls esclarece, no Prefácio à Uma Teoria da Justiça, da seguinte forma:

[...] minha intenção foi formular uma concepção da justiça que fornecesse uma alternativa razoavelmente sistemática ao utilitarismo, que, de uma forma ou de outra, dominou por um longo tempo a tradição anglo-saxônica do pensamento político. A razão principal para buscar essa alternativa é, no meu modo de pensar, a fragilidade da doutrina utilitarista como fundamento das instituições da democracia constitucional. (RAWLS, 2002, p. 14).

Rawls não depõe a favor da premissa de que o utilitarismo possa explicar as liberdades e direitos fundamentais dos cidadãos como pessoas livres e iguais, uma exigência fundamental para as instituições democráticas, afirmando que "muitas vezes parecemos forçados a escolher entre o utilitarismo e o intuicionismo", apesar de afirmar parecer ser o utilitarismo o conceito mais racional de justiça (RAWLS, 2002, p. 22). Destarte a argumentação contratualista consiste em uma alternativa mais consistente ao "princípio da utilidade", uma vez que esse argumento busca efetivamente explicar a exatidão da justiça mediante a presunção de que seus princípios surgem de um acordo entre indivíduos, indivíduos esses livres e independentes numa situação original de igualdade ${ }^{8}$. O que, de certa forma, reflete a integridade e a igualdade soberana das pessoas racionais que são partes fundamentais no contrato 9 .

Sobre essa questão, Rawls (2002, p. 64-65) evidencia:

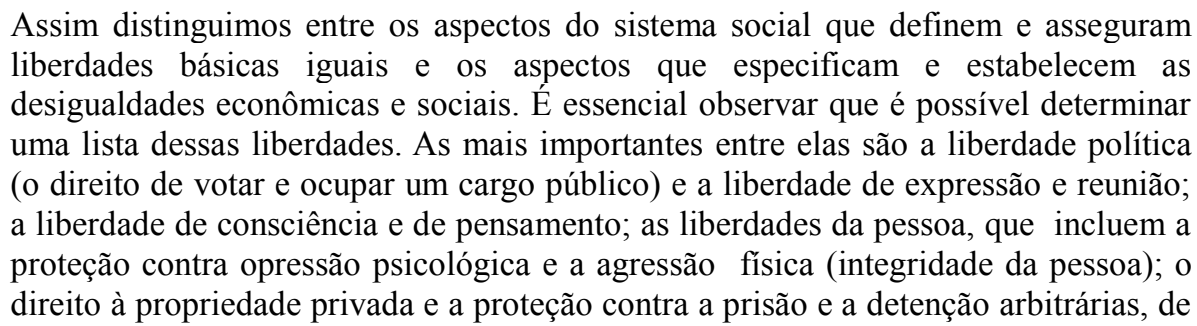


acordo com o conceito de estado de direito. Segundo o primeiro princípio, essas liberdades devem ser iguais.

Se o utilitarismo visa ao bem-estar ou a felicidade da sociedade como um todo, em detrimento do bem-estar geral de cada indivíduo, a teoria da justiça de Rawls determina de certa forma, um objetivo diferenciado, a saber: "o bem-estar do indivíduo, de acordo com as suas liberdades básicas, em detrimento do maior proveito que a oferta pelo bem-estar geral poderia angariar para a sociedade" (ALTABLE, 1993, p. 23). Portanto, estabelecidos esses princípios, Rawls considera que a sociedade bem ordenada seja aquela projetada unicamente para promover o bem de todos os indivíduos, assim como regulada por uma concepção pública de justiça. Trata-se de uma sociedade na qual todos os indivíduos aceitam os mesmos princípios de justiça, e as instituições sociais fundamentais buscam de modo geral atender e ajustar-se a esses mesmos princípios. Desta forma, segundo Altable (1993, p. 23), "havendo exigências por parte de um ou mais membros da sociedade, a justiça detém esses impulsos para estabelecer os vínculos de uma convivência harmoniosa, pois o sentido de justiça leva uns e outros a vigiarem-se, tornando-se, assim, uma sociedade segura".

Justamente por considerar que não se trata de uma solução convincente para todos, Rawls argumenta que a justiça como equidade, numa visão contratualista, consiste segundo ele em duas partes fundamentais e interligadas, a saber: "Uma interpretação da situação inicial e a do problema da escolha que nela se apresenta e um conjunto de princípios que segundo se procura demonstrar, seriam acordados" (RAWLS, 2002, p. 19). Não obstante, as duas partes desta teoria relacionadas tanto a justiça como a equidade e outras visões contratualistas são polêmicas. Na concepção de Rawls, pode-se aceitar a primeira parte dessa teoria (ou alguma visão dela), mas não a segunda e vice-versa. Compreende-se, com isso, que a proposta de Rawls (2002) consiste em sustentar uma concepção mais apropriada dessa situação, no qual conduz o princípio de justiça distinto do utilitarismo e do perfeccionismo, justificando assim a concepção contratualista como uma alternativa viável para essas tendências. Todavia, fica evidente que o próprio concorda que seus argumentos possam ser facilmente contestados, mesmo que seja admitido formalmente que o argumento contratualista seja um modo útil de refletir acerca das teorias éticas e, consequentemente, de apresentar seus fundamentos.

Justifica-se, portanto, a opção de Rawls em utilizar o viés contratualista mediante o critério relativo a promoção de "consenso inicial" entre as pessoas acerca dos princípios de justiça que regularão a estrutura básica da sociedade e, consequentemente, regularão todos os acordos subsequentes, a fim de que sejam justos e, sobretudo, equitativos. Seguindo essa 
perspectiva, Rawls (2002), com uma posição oposta ao contratualismo moderno ou clássico, redefine o argumento do contrato inicial posicionando-o não como um mero acordo para a instauração de uma determinada forma de governo, mas para uma escolha coletiva que objetiva à adoção de princípios de justiça para a estrutura básica da sociedade ${ }^{10}$. Sendo assim, a concepção de justiça, sob a ótica normativa, tal qual Rawls determina, possui "o seu fundamento direto no argumento contratualista enfatizando, sobretudo, a noção de justiça e não de legitimidade para engendrar as suas pretensões teóricas e políticas" (DELANEY, 1983, p. 23).

Diante de tal critério, infere-se o motivo pelo qual não há pretensão alguma do filósofo em reformular uma concepção de contrato original como uma forma de estabelecer um novo tipo de sociedade ou mesmo legitimar uma nova forma de governo. Ao contrário do que parecer ser, o teórico reitera a afirmação acerca dos seus propósitos legítimos, a saber, "a ideia norteadora é que os princípios de justiça para a estrutura básica da sociedade constituem o objeto do acordo original" (Rawls, 2002, p.3). O comprometimento argumentativo de Rawls com as clausuras do contratualismo clássico, excepcionalmente aqueles contidos em Uma Teoria da Justiça, propõe claramente "apresentar uma concepção de justiça que generalize e erga a um nível mais alto de abstração a conhecida teoria do contrato social conforme encontrada em Locke, Rousseau e Kant” (Rawls, 2002, Prefácio, p. XXIII).

Sobre isso, RAWLS (2002, p.18) comenta:

\begin{abstract}
O mérito da terminologia do contrato é que ela transmite a idéia de que princípios da justiça podem ser concebidos como princípios que seriam escolhidos por pessoas racionais e que assim as concepções de justiça podem ser explicadas e justificadas. A teoria da justiça é uma parte, talvez a mais significativa, da teoria da escolha racional. Mais ainda, os princípios da justiça tratam de reivindicações conflitantes sobre os benefícios conquistados através da colaboração social; aplicam-se às relações entre várias pessoas ou grupos. A palavra 'contrato' sugere essa pluralidade, bem como a condição de que a divisão apropriada de benefícios aconteça de acordo com princípios aceitáveis para todas as partes. A condição de publicidade dos princípios da justiça é também sugerida pela fraseologia contratualista. Assim, se esses princípios são o resultado de um consenso, os cidadãos têm conhecimentos dos princípios que os outros seguem. É típico das teorias contratualistas ressaltarem a publicidade dos princípios políticos. Finalmente há uma longa tradição da doutrina contratualista. Expressar o vínculo com essa linha de pensamento ajuda a definir idéias e está de acordo com a lealdade natural. Há, portanto várias vantagens o uso do termo 'contrato' (...).
\end{abstract}

Não obstante, a referência ao acordo original, assim como a metodologia utilizada pelo teórico na aplicação da justiça, depõe a favor do argumento de que a teoria da justiça representa um exemplo do argumento contratualista entre tantos argumentos possíveis de 
aplicação da justiça aos termos de um acordo. Sobre essa questão Care (1969, p. 90) ressalta, “cada qual tem a pretensão de desenvolver uma interpretação da situação inicial de escolha de uma determinada forma, cujo resultado é apresentado como a solução mais adequada para o problema ao qual fundamental suas respectivas argumentações”.

Existe, portanto, um conflito explícito entre os pressupostos do utilitarismo e a concepção de justiça pretendida por Rawls, na medida em que considera determinadas regras de justiça em uma posição essencialmente secundária. Na perspectiva utilitarista, a satisfação dos desejos individuais, amparados por um princípio de respeito à liberdade individual, são valorizados pelo simples motivo de não ser absolutamente necessário que tais desejos sejam amplamente defendidos, pois as instituições devem estar organizadas de forma a admitir que esse desejo seja realmente alcançado. Quando Rawls critica o utilitarismo, pretende evidenciar que a estrutura teleológica do utilitarismo é absolutamente equivocada. Sobre isso, o filósofo (2002) argumenta que o utilitarismo não faz uma relação adequada entre os conceitos do correto e do bem, na medida em que definem uma concepção de bem independente do correto e, também, consideram o correto como aquilo que maximiza o bem.

Nesse caso, evidencia Care (1969, p. 100), “o valor intrínseco é levado em conta ao decidir o que é justo, e esta forma de bem-estar social defendida pelo utilitarismo, visa também organizar as instituições para situações que julga que determinados desejos atinjam o maior número de pessoas individualmente beneficiadas". Ao contrário, portanto, no contexto da teoria da justiça como equidade, aqueles que constituem o grupo social se fundamentam também por um princípio de liberdade, mas, no sentido de que todos sejam tratados igualmente, sem qualquer tipo de privilégios, ou outras formas de vantagens individuais em detrimento dos demais membros do grupo social ${ }^{11}$.

Levando em conta esse argumento, torna-se perfeitamente possível vislumbrar que a justiça como equidade, tal como expõe Rawls, não pressupõe que a justiça e a equidade sejam termos absolutamente correlatos. Na verdade, o significado de equidade, no âmbito da teoria da justiça, representa o que é de mais característico da situação em que é efetivamente justo o acordo no qual resultam princípios de justiça, uma vez que, os pressupostos da equidade, segundo Eshete (1974, p. 45), "permitem uma perspectiva da posição original como um jogo imparcial mediante o qual se busca um consenso direto e abstrato acerca dos princípios de justiça que devem ser realmente escolhidos".

Diante disso, Vallespín Oña (1985, p. 23) afirma que "o mérito do contrato proposto pela posição original é encontrado pela transmissão dos princípios de justiça extraídos de princípios racionais dos próprios cidadãos e que se aplicam às relações entre várias pessoas". 
Sendo assim, a utilização do argumento contratualista como uma crítica sistemática aos termos do utilitarismo depõe a favor da insuficiente desse na tentativa de responder às demandas do atual estágio de desenvolvimento das sociedades contemporâneas. O utilitarismo, segundo Rawls (2002), interessa-se exclusivamente na viabilidade para a maximização da felicidade coletiva, em detrimento ao modo como a mesma está efetivamente distribuída. Nesses termos, o utilitarismo não pode realmente fornecer um embasamento para a distribuição justa da felicidade e, por consequência, tende ao fracasso enquanto uma teoria de justificação da moral do Estado ${ }^{12}$.

Com base no exposto, pode-se verificar uma aderência argumentativa do contratualismo proposto por Rawls à sua filosofia moral, uma vez que o que deve ser considerado justo é aquilo que é o melhor para a sociedade. Diante disso, a sociedade justa, ou seja, a sociedade bem estruturada ou ordenada deve ter o seu funcionamento de tal modo que as pessoas possam efetivamente conviver com as diferenças religiosas, étnicas e culturais, enquanto pessoas livres e iguais, sem causas que interfiram efetivamente na sua dignidade. Se for assim, a teoria da justiça apresenta-se com um procedimento de construção procedimental capaz de representar, primeiramente, a ideia central de que os princípios da justiça para a estrutura básica devam ser necessariamente objeto de um acordo original (KOLM, 2000). Segundo, da mesma forma, tais princípios caracterizam-se por regular todos os acordos subsequentes e especificar os tipos de cooperação social e, consequentemente, as formas de governos a serem socialmente estabelecidas. Indistintamente, todos esses termos desembocam numa tentativa de fundamentação do procedimento pelo qual será viabilizada a construção de uma sociedade livre e equitativamente justa.

Uma vez delineado as determinações do argumento contratualista baseado na refutação de Rawls aos princípios do utilitarismo passa-se, diante dos propósitos a serem atingidos, para a exposição acerca da relação entre contratualismo e pluralismo razoável. O exame dessa relação evidencia a concepção de justiça que possibilita conciliar as diferentes visões de mundo em torno de um elemento comum objetivando obter um consenso por sobreposição de doutrinas abrangentes razoáveis, não possui, portanto, qualquer pretensão de se declarar a única visão correta, de modo a excluir todas as demais. A proposta de Rawls diz respeito a uma aplicação fundamental na filosofia do que se denomina de "princípio da tolerância" (RAWLS, 2002).

\section{Contratualismo e pluralidade de escolhas: entre o liberalismo político e o plurarismo}




\section{razoável}

Na perspectiva de Rawls, segundo Robins (1976), diante das condições históricas e sociais que engendraram o surgimento do Estado democrático liberal, como, por exemplo, as guerras relacionadas à religião dos séculos XVI e XVII, não há critérios suficientes para reconhecer uma doutrina moral abrangente como moderadora da estrutura básica da sociedade. A sua explicação sobre esse fato advém, sobretudo, porque admite que "tais doutrinas admitem somente uma única concepção do bem como legítima e, portanto, aquela a ser irremediavelmente seguida por todos" (RAWLS, 1993, p. 26). Como consequência, essas doutrinas tendem a negar veementemente o fato do pluralismo razoável, isto é, negam a possibilidade da existência de múltiplas concepções do bem e crenças defendidas pelas pessoas numa mesma sociedade democrática liberal, que, porventura sejam conflitantes e incomensuráveis entre si, mas que sejam compatíveis com a racionalidade.

De acordo com Rawls (1993, p.22),

O liberalismo político entende o facto do pluralismo razoável como um pluralismo de doutrinas abrangentes, que inclui as doutrinas religiosas e não religiosas. Este pluralismo não é visto como um desastre, mas antes como o resultado natural das atividades da razão humana no contexto de instituições livres duradouras.

Diante desses termos, a questão proposta por Rawls (1993), em relação ao pluralismo, diz respeito ao modo como descobrir uma base pública sólida para um acordo político que seja informado e totalmente voluntário entre cidadãos livres e iguais, isto é, o modo como utilizar-se de uma base pública sólida sem utilizar-se do recurso autocrático que imponha a ordem pela força. Conforme os termos da argumentação da teoria da justiça, a estabilidade social somente poderá ser assegurada se for baseada solidamente em atitudes sociais e políticas públicas de um povo. Em relação a esse pressuposto, Rawls (2002) enfatiza a sua preocupação na resolução do problema da estabilidade através de uma investigação na qual se estabeleça um fundamento para um acordo político como uma das tarefas fundamentais da filosofia política.

Desse modo, encontrar um fundamento apropriado para o princípio da cooperação social e, consequentemente, da ordem social e política torna-se de extrema relevância para uma sociedade democrática no qual o pluralismo razoável de concepções de bem e incomensuráveis entre si convivem indiscriminadamente. Por essa razão, Rawls (2002) justifica o propósito da reflexão sobre a estabilidade baseada no argumento que essa seria, sobretudo, a tarefa mais essencial da filosofia política, cujos pressupostos teóricos estão 
impreterivelmente interligados ao argumento contratualista.

Em relação a esse pressuposto, na perspectiva de Kukhatas e Pettit (1999, p. 34), a função da argumentação contratualista não deve limitar-se somente em auxiliar a escolha dos "agentes contratantes", mas sobretudo, pacificar os conflitos e as divergências sociais. Ainda segundo Kukhatas e Pettit (1999), em relação ao propósito heurístico, ou seja, o fornecimento dos meios adequados a partir dos quais as pessoas possam escolher a opção viável e, portanto, a mais justa aos interesses sociopolíticos, a função do argumento contratualista de cunho estritamente hipotético, não estabelece obrigações reais, uma vez que as pessoas não são legalmente obrigadas a cumprir os termos acordados na situação hipotética. Desse modo, conforme menciona Rodilla (1986, p. 43) “a importância fornecida em relação a uma situação hipotética é, sobretudo, o pacificar os conflitos de interesses sociais, amenizando consequentemente as divergências sociais". Com relação a esse fato, na concepção modelo da posição original, o contrato estabelecido é imprescindível como elemento pacificador, pois através de sua hipótese contratual todos podem verificar que a escolha dos princípios de justiça e da estrutura básica da sociedade possuem realmente respaldo em um procedimento justo.

Diante disso RAWLS (2002, p.16) esclarece,

\begin{abstract}
Sustentarei que as pessoas na situação inicial escolheriam dois princípios bastante diferentes: o primeiro exige a igualdade na atribuição de deveres e direitos básicos, enquanto o segundo afirma que as desigualdades econômicas e sociais, por exemplo, desigualdades de riqueza e autoridade, são justas apenas se resultam em benefícios compensatórios para cada um, e particularmente para os membros menos favorecidos da sociedade [...].
\end{abstract}

O que Rawls (2002) adverte é simplesmente para a concepção de que, diante de uma situação hipotética contratual, as divergências particulares e morais impedem a admissão e a escolha imparcial dos princípios de justiça como um procedimento eminentemente justo. Sendo assim, tal procedimento confronta os objetivos específicos de várias doutrinas morais ou religiosas, as quais se veem obrigadas a negar ou mutilar seus respectivos conceitos. $\mathrm{Na}$ verdade, essas doutrinas são "obrigadas a rever sua postura diante de outras doutrinas", menciona Rawls (2002).

Diante desse fato, as limitações impostas pelo contrato hipotético possibilitam que as pessoas possam conviver pacificamente entre si, respeitando-se mutuamente como pessoas livres e iguais. No contexto dessa discussão, o consenso sobreposto ou o consenso por sobreposição estabelece-se como um modelo altamente relevante na perspectiva contratulaista 
do pluralismo, "uma vez que representa uma concepção política que recebe o apoio dos membros das diversas doutrinas", afirma Milo (1995, p. 23).

Se for realmente assim, pode-se afirmar que o modo de atuação do consenso por sobreposição não se limita apenas a uma mera tolerância às diferenças conforme o oportunismo ou os benefícios que tal tolerância pode acarretar. Ao contrário, o que se pode compreender é que o consenso apresenta como conteúdo de uma concepção política, as ideias fundamentais que constituem a diversidade da cultura pública democrática. Nesse contexto, a proposta evidenciada por Rawls (2002) implica nada mais do que a disponibilidade de determinados valores culturais de uma determinada doutrina abrangente agregada respectivamente a diversos outros valores de distintas doutrinas resultem, incontestavelmente, no significativo conteúdo de uma concepção política, a qual identifica em todas as concepções do bem os elementos racionais e razoáveis mais adequados aos propósitos democráticos.

Seguindo os termos dessa interpretação, o liberalismo político proposto por Rawls, tal como explica Kukathas e Pettit (1999), compreende um determinado liberalismo que não depende de nenhum ideal moral liberal em particular, como a autonomia, por exemplo. Diante dessa constatação, para os referidos intérpretes o liberalismo do filósofo em questão não se distancia do que se concebe por liberalismo, o que diferencia é a sua observância relativa à importância da tolerância e, sobretudo, da defesa de um sistema de governo orientado por princípios que não pressupõem uma determinada forma de boa vida como sendo realmente a melhor.

Do que foi mencionado, nada mais coerente do que posicionar o "overlapping consensus" na função de assegurar a estabilidade numa sociedade na qual o pluralismo é o resultado inevitável do funcionamento das instituições livres e do uso pleno da razão, ao passo que representa uma concepção de legitimidade política. Como consequência desse fato, infere-se a possibilidade do reconhecimento de que os cidadãos sejam realmente livres e iguais e, mediante esse reconhecimento, possam efetivamente pensar a possibilidade de que toda concepção liberal deva proceder em um exame da sua própria estabilidade, de tal modo que cada cidadão possa afirmá-la livremente.

Na perspectiva de Weber (2011 p. 137),

Pode-se observar que o campo de abrangência da Filosofia Política em Rawls, aqui, é claro. Para chegar a um consenso ela deve manter independência e autonomia em relação aos problemas e controvérsias de outras áreas da Filosofia, como por exemplo, os ligados à religião, às questões morais, etc. Essa independência não significa indiferença ou ceticismo. Para obter o respaldo (acima referido) a 
concepção de justiça deve ocupar-se de valores políticos essenciais e endossáveis.

Uma vez dito isso, uma indagação se impõe imediatamente em relação a esse pressuposto: se o pluralismo constitui-se em uma característica fundamental das sociedades democráticas modernas, torna-se possível, da mesma forma, redimensioná-lo como um dos fundamentos básicos de uma concepção de justiça social? Se for dessa forma, uma concepção de justiça social, ou seja, a justiça como equidade, terá de estabelecer um fundamento que viabilize a cooperação entre os defensores de diferentes doutrinas abrangentes? Esse será, portanto, a proposta de Rawls quando reflete as determinações do consenso por sobreposição.

Sobre esse ponto da argumentação, Guillarme $(1996,326)$ esclarece:

O consenso por sobreposição é um mecanismo de justificação das instituições políticas e jurídicas, fazendo com que a sociedade adote uma pauta mínima de valores, cuja adesão seja a mais ampla entre seus diversos segmentos, independentemente do credo religioso, da orientação político-ideológica ou da filosofia de seus integrantes. A existência de um consenso sobreposto é sinal de pluralismo e democracia, bem assim de valores liberais (o que não pode ser confundido com o sentido do liberalismo econômico).

A concepção política de justiça apresentada por Rawls fornece adequadamente uma resposta condizente para o problema do pluralismo nas sociedades contemporâneas, pois apresenta a justiça como a qualidade mais importante nas instituições ${ }^{13}$. De certa forma, essa qualificação da justiça eleva-a a uma discussão preponderante na temática da filosofia política, uma vez que a legitimidade de uma democracia não suprime possíveis injustiças das decisões para determinados grupos, nem ao menos garante estruturas confiáveis em relação a ótica da justiça para questões de distribuição de direitos e deveres. Com efeito, por meio da construção de um espaço ampliado de debate denominado "razão pública", Rawls (2002) sustenta que uma sociedade bem-ordenada não pode existir sem um espaço ampliado de participação para que cidadãos livres e iguais discutam sobre aspectos essencialmente relacionados aos problemas decorrentes da justiça.

De fato, Rawls ao elaborar uma concepção de justiça no qual possibilita conciliar as diferentes visões de mundo em torno de um elemento comum objetivando obter um consenso por sobreposição de doutrinas abrangentes razoáveis, não possui, portanto, qualquer pretensão de se declarar a única visão correta, de modo a excluir todas as demais ${ }^{14}$. A sua proposta nada mais é do que a de aplicar na filosofia o princípio da tolerância. Diante do fato do pluralismo, a elaboração de uma concepção de justiça não deve basear-se em doutrinas abrangentes que sejam absolutamente incapazes de proporcionar uma base adequada para o acordo entre os 
cidadãos de uma comunidade, razão pela qual a teoria da justiça deve descartar visões metafísicas, limitando-se, consequentemente, a construir concepções políticas de justiça (DIETERLE, 1992).

Seguindo essa determinação, na formulação final da teoria da justiça, pode-se conceber que a construção do valor do justo não se baseia em nenhuma crença particular, mas sim em valores políticos que são comuns a todos. Nesse caso, o problema fundamental da justiça consiste, sobretudo, na busca de uma base mínima de acordo que respeite os princípios contidos na constituição, embora esse seja o único elemento em torno do qual se pode obter um consenso em uma sociedade democrático-pluralista. Em outros termos, expõe Dieterle (1992, p. 12) "através da ideia de um consenso por sobreposição que se realiza inicialmente a justificação pelo qual a sociedade moderna, caracterizada pelo fato do pluralismo razoável, pode alcançar posteriormente a justificação pública". Essa justificação, por sua vez, garante as bases de uma unidade social duradoura e profunda de uma sociedade caracterizada, sobretudo, pelo fato de constituir-se pelo pluralismo e pelo multiculturalismo.

Desse modo Rawls (1999, p. 84),

\begin{abstract}
Deixamos de lado as doutrinas abrangentes que existem hoje, que já existiram ou que podem vir a existir. A ideia não é que os bens primários são equitativos em relação às concepções abrangentes do bem associadas a essas doutrinas, por determinarem um equilíbrio equitativo entre elas, mas sim que são equitativas em relação a cidadãos livres e iguais, enquanto pessoas que tem essas concepções.
\end{abstract}

Por sua vez, segundo Altable (1995. p. 136), "a tolerância e seus limites somente se justificam se estão emparelhadas com o princípio da igual liberdade, e jamais se justificam por razões meramente pragmáticas, nem ao menos por doutrinas filosóficas ou metafísicas". Sendo assim, qualquer que seja imposta uma limitação à liberdade esta apenas poderá justificar-se a fim de evitar uma injustiça maior. Por outro lado, a restrição às razões compartilháveis por todos não significam, porém, que a teoria da justiça considere suas respectivas razões como realmente superiores aos motivos religiosos ou filosóficos, nem é a eles indiferente ou cética (RAWLS, 2005a, p. 214).

O propósito de Rawls, por conseguinte, não consiste em negar em absoluto essas doutrinas, mas esquivar-se de maiores pressuposições em favor de uma política acessível a todos. Com efeito, conforme destaca o filósofo, os intolerantes devem ser tolerados pelo mesmo motivo da tolerância de outras doutrinas, ou seja, sem qualquer impedimento ou supressão das suas respectivas liberdades religiosas ${ }^{15}$. Em relação a esse pressuposto, o Estado, na sua racionalidade, deve proteger a liberdade fundamental dos indivíduos de 
escolher livremente seus projetos de vida. Nesse contexto, a mera intolerância não é razão para suprimir uma doutrina (RAWLS, 2000).

Diante dos termos elencados, adianta Audard (2000), a concepção de consenso de sobreposição, ainda esteja relacionada à estabilidade da teoria, torna-se, por conseguinte um elemento imprescindível de justificação no âmbito da teoria da justiça ${ }^{16}$. Portanto, na ausência desse elemento teórico, a concepção de justiça não seria amplamente justificada, apesar do respaldo da posição original. Diante dessa relevância conceitual, Rawls legitima a questão da estabilidade ao conectá-la à questão de uma legitimidade liberal, a qual, segundo ele próprio afirma, é "assegurada com motivação suficiente e adequada, adquirida sob instituições justas" (RAWLS, 2000, p. 142).

$\mathrm{Na}$ perspectiva do filósofo, a justiça como equidade somente poderia ser considerada razoável se ao menos estiver atrelada às razões de cada cidadão. Nesse caso, considerar-se-ia a sua concepção política de justiça como um módulo que pode perfeitamente encaixar-se e apoiar-se em algumas dessas doutrinas que sejam evidentemente razoáveis (RAWLS, 2000, p. 144). Tal "módulo" evidenciado, no contexto da justiça, explica irremediavelmente o sentido do consenso de sobreposição. Desse modo, conforme afirma Audard (2007, p. 197), “o consenso de sobreposição é o estável e duradouro acordo entre doutrinas abrangentes razoáveis, no qual cada uma apoia a concepção de justiça a partir de seu próprio ponto de vista".

Segundo Zambam (2004, p. 89)

O consenso se dá no campo da política e recebe o respaldo das principais instituições. Especial destaque deverão ter os valores políticos fundamentais que estão expressos nos princípios e ideais dos membros da sociedade. Em torno dos valores políticos devem ser formulados os acordos, pois neles se manifestam as divergentes doutrinas compartilhadas no interior da sociedade. É preciso ressaltar que, para o liberalismo político, é inconcebível o uso do poder político para impor doutrinas abrangentes próprias, sejam elas de natureza religiosa, filosófica ou moral.

Considerando, por sua vez, essa pressuposição, Rawls (2000, p. 153) concebe o sentido no qual a tolerância é aplicada à própria filosofia na medida em que propõe "deixar os próprios cidadãos resolverem as questões de religião, filosofia e moral de acordo com as visões que eles livremente afirmam”. Nesses termos, os cidadãos são persuadidos a apoiar o consenso de sobreposição "seja como verdadeiro, seja como razoável, do modo como a visão [abrangente] permitir" (RAWLS, 2000, p. 151). Portanto, a concepção abrangente pluralista 
considera, por conseguinte, haver "diferentes domínios de valor, dos quais o político é somente um deles", afirma Rawls (2000, p. 170).

Nesses termos, o acordo prudencial entre as visões abrangentes e o Estado reflete, na concepção de Rawls, um equilíbrio de razões do ponto de vista das doutrinas abrangentes dos cidadãos, na medida em que lhes permitem respeitar os valores políticos e os limites da razão pública. Diante desse contexto, Zambam (2004) evidencia que o próprio cidadão que decidirá o que considera ser a sua respectiva perspectiva de justiça verdadeira, ou simplesmente razoável. Tal consideração explica, por conseguinte, a proposta de Rawls de buscar uma base ampla de apoio para a concepção de justiça, evitando aproximar-se de determinadas controvérsias filosóficas, morais e religiosas. Não obstante, na visão de Kymlicka (1996, p. 46), tal apoio seria impossível no âmbito da política liberal, pois aceitar a autonomia em contextos políticos inevitavelmente possibilita o seu exercício mais geral.

Desse modo Cittadino (2000, p. 1),

O pluralismo, entretanto, possui, pelo menos, duas significações distintas: ou o utilizamos para descrever a diversidade de concepções individuais acerca da vida digna ou para assinalar a multiplicidade de identidades sociais, específicas culturalmente e únicas do ponto de vista histórico.

Tal consideração desenvolvida por Kymlicka (1996) remete-se diretamente a acusação dos críticos de Rawls de que a teoria da justiça corresponderia a uma espécie de doutrina abrangente e, portanto, incapaz de conciliar-se com o fato do pluralismo. Esta interpretação está diretamente relacionada à demonstração da concepção de justiça como equidade como integrante de uma teoria moral que, por conseguinte, desvelaria uma doutrina filosófica ainda maior. Não obstante, o que consequentemente direciona o empreendimento político de Rawls quando o mesmo propõe uma discussão sobre liberalismo, mais precisamente sobre liberalismo político, é a sua concepção de pluralismo. Obviamente, essa preocupação não é despretensiosa, uma vez que a questão da tolerância acompanha todo o debate político da sua contemporaneidade tornando, por conseguinte, uma das grandes preocupações de Rawls, não só no âmbito da sua análise política interna, como também nas questões da política internacional.

Segundo evidencia Pogge (2007), torna-se imprescindível uma atenção maior a qualquer referência ao conceito de tolerância antes, porém, de especificar a qual tipo de pensamento liberal está se remetendo. O motivo dessa atenção refere-se particularmente a ênfase fornecida, pelo liberalismo rawlsiano à ideia de pluralismo, uma vez que o modo como o filósofo enfatiza o liberalismo, através do conceito de justo, demonstra a sua preocupação 
sem, no entanto, remeter-se ou aproximar-se cair aos termos do autoritarismo. Como base nisso, fica evidente a relação sugerida por Rawls entre os termos do liberalismo político e as determinações de uma sociedade constituída pela pluralidade, pelo qual se torna imprescindível os princípios de liberdade e igualdade (POGGE, 2007, p. 23).

Em outros termos, o pressuposto fundamental do liberalismo político, tal como expressa Rawls, é o modo como a sociedade contemporânea considerada plural determina seus respectivos princípios de liberdade e igualdade, sem que haja uma imposição de uma doutrina sobre as demais. Uma vez determinado essa questão, Rawls respalda-se teoricamente na consecução da diferenciação que entre o liberalismo político e os liberalismos abrangentes. Portanto, a obtenção dessa distinção deve necessariamente a pressuposição de que a ideia de tolerância permanece um desafio para as instituições políticas nas sociedades hodiernas, cujas características mais marcantes são a pluralidade e multiculturalidade (DIETERLEN, 1992). Diante disso, pode-se conceber que as soluções fornecidas por Rawls, no contexto da relação entre justiça, pluralismo e contratualismo, não devem ser consideradas como definitivas, mas, sobretudo, como elementos fundamentais para enriquecer o debate sobre essa questão tão necessariamente polêmico e norteador para a solidificação do ambiente democrático nas sociedades contemporâneas. 


\section{Notas:}

${ }^{1}$ Doutor em Filosofia pela UFRJ. Realiza Estágio de Pós-Doutorado no Programa de Pós-graduação em Direito e Sistemas de Justiça da UFMA. Professor Pesquisador da Universidade CEUMA/MA (UNICEUMA). Pesquisador da FAPEMA/CNPq. Autor do livro: O problema da liberdade e a liberdade como problema em Thomas Hobbes (Ed. Multifoco).

2“Afigurou-se para muitos filósofos, e isso parece encontrar apoio nas convicções do senso comum, que fazemos, como uma questão de princípio, uma distinção entre as exigências da liberdade e do correto, de um lado, e o desejo de aumentar o bem-estar de outro; e que damos certa prioridade, quando não um peso absoluto às primeiras exigências." (RAWLS, 2002, p. 37-38).

${ }^{3} \mathrm{O}$ contratualismo é objeto de diversas críticas pelos mais variados teóricos da filosofía política contemporânea. Algumas vezes denotam o aspecto por demais formal e artificial, de outra forma apontam não haver nenhuma garantia da manutenção dos acordos, sem qualquer consideração para outros recursos coercitivos externos tão engenhosos quanto o próprio artifício do contrato. Não obstante, apesar desses argumentos, outros filósofos assumiram o argumento contratualista como a mais eficaz para explicar os problemas advindos pela motivação, pela cooperação social e mesmo como alternativa mais adequada para ocupar o debate acerca da moralidade.

${ }^{4} \mathrm{O}$ termo 'cooperação', utilizado no contexto dessa discussão possui um significado aproximado a uma atividade guiada por regras publicamente reconhecidas e por procedimentos aceitos pelos cooperadores. Por outro lado, pode-se afirmar que os termos indicados como equitativos correspondem ao modo como cada participante pode razoavelmente aceitá-los com a condição de que todos os outros os aceitem, ou possam aceitá-los, igualmente.

5“'Em uma sociedade liberal justa, as liberdades fundamentais são iguais para todos - elas definem uma estrutura institucional que garante os mesmos direitos, isenções, prerrogativas e oportunidade para todos. Mas o valor disso não é igual para todos. A pobreza e a ignorância incapacitam uma pessoa de se valer desses direitos e oportunidades que lhes são institucionalmente garantidos. E, como Rawls admite, mesmo em uma sociedade bem ordenada os que têm mais renda e riqueza estarão sempre mais bem posicionados para tirar proveito desses recursos institucionais" (VITA, 2007, p. 210-1).

6 “A razão principal para buscar essa alternativa é, no meu modo de pensar, a fragilidade da doutrina utilitarista como fundamento das instituições da democracia constitucional. Em particular, não credito que o utilitarismo possa explicar as liberdades e direitos básicos dos cidadãos como pessoas livres e iguais, uma exigência de importância absolutamente primordial para uma consideração danstituições democráticas” (2002, p. XIV).

7 "O conceito de racionalidade invocado aqui, a não ser por uma característica essencial, é aquele conceito clássico famoso na teoria social. Assim, de forma genérica, considera-se que uma pessoa racional tem um conjunto de preferências entre as opções que estão a seu dispor. Ela classifica essas opções de acordo com a sua efetividade em promover seus propósitos; segue o plano que satisfará uma quantidade maior de seus desejos, e que tem as maiores probabilidades de ser implementado com sucesso" (RAWLS, 2002, p.154).

8 "Pode-se afirmar que uma pessoa é partidária do princípio de utilidade quando a aprovação ou a desaprovação que dá a alguma ação, ou a alguma medida, for determinada pela tendência que, no seu entender, tal ação ou medida tem a aumentar ou a diminuir a felicidade da comunidade; ou, em outras palavras, pela sua conformidade ou não-conformidade com as leis ou os ditames da utilidade (BENTHAM, 1989, p. 5).

${ }^{9}$ Rawls (2002, p. 43-4) afirma que “a característica distintiva, portanto, das visões intuicionistas [...] está [...] na importância proeminente que conferem ao apelo às nossas capacidades intuitivas, sem dispor da orientação de critérios implícitos e reconhecidamente éticos. $\mathrm{O}$ intuicionismo nega que exista uma solução explícita e útil para o problema da prioridade".

${ }^{10}$ Sobre essa questão Rawls comenta em The Sense of Justice, de 1963:" "O objetivo da construção analítica é derivar os princípios de justiça que se aplicam às instituições. Como as pessoas vão agir nas circunstâncias específicas em que, como as regras especificam, é a sua vez de fazer o seu par é uma questão completamente diferente. Aqueles envolvidos em uma instituição será, de facto, normalmente fazer a sua parte, se eles se sentem 
vinculados à ação dos princípios que eles reconhecem nas condições da construção analítica. Mas seu sentimento ligado desta forma não é em si explicada por esta construção, e não pode ser contabilizado como tempo que as partes são descritas apenas pelo conceito de racionalidade" (Rawls, 1999, p. 285).

${ }^{11} \mathrm{Na}$ obra $O$ Liberalismo Político, Rawls enfatiza que o que "a teoria da justiça deve regular são as desigualdades nas perspectivas de vida dos cidadãos decorrentes de posição social inicial, vantagens naturais e contingências históricas. Mesmo quando essas desigualdades não são muito grandes em certos casos, seus efeitos podem ser muito importantes, pois, ao longo do tempo, têm consequências cumulativas significativas" (RAWLS, 2000, p. 323).

12 “(...) certamente quero sustentar que a concepção mais apropriada dessa situação conduz a princípios de justiça contrários ao utilitarismo e perfeccionismo, e que portanto a doutrina do contrato oferece uma alternativa para essas visões. Todavia é possível contestar esse ponto de vista mesmo concedendo que o método contratualista seja uma maneira útil de estudar teorias éticas e de apresentar os pressupostos em que se baseiam" (RAWLS, 2002, p. 17).

${ }^{13}$ Sobre a concepção de justiça Rawls menciona (2002, p. 3-4) "A justiça é a primeira virtude das instituições sociais, como a verdade o é dos sistemas de pensamento. Embora elegante e econômica, uma teoria deve ser rejeitada ou revisada se não é verdadeira; da mesma forma leis e instituições, por mais eficientes e bem organizadas que sejam devem ser retomadas ou abolidas se são injustas. Cada pessoa possui uma inviolabilidade fundada na justiça que nem mesmo o bem-estar da sociedade como um todo pode ignorar. Por essa razão, a justiça nega que a perda da liberdade de alguns se justifique por um bem maior partilhado por outros. Não permite que os sacrifícios impostos a uns poucos tenham menos valor que o total maior das vantagens desfrutadas por muitos. Portanto numa sociedade justa as liberdades da cidadania igual são consideradas invioláveis; os direitos assegurados pela justiça não estão sujeitos à negociação política ou ao cálculo de interesses sociais. A única coisa que nos permite aceitar uma teoria errônea é a falta de uma teoria melhor; de forma análoga, uma injustiça é tolerável somente quando é necessária para evitar uma injustiça ainda maior. Sendo virtudes primeiras das atividades humanas, a verdade e a justiça são indissociáveis".

14،“A existência de doutrinas que negam uma ou mais liberdades democráticas é, por si, um fato permanente da vida, ou assim parece. Isso nos impõe a tarefa prática de contê-las - como se contém uma guerra ou uma doença -, para que não subvertam a justiça política" (Rawls: 2000, nota 19 da conferência II).

15،"Desse modo, como os cidadãos têm capacidades morais, eles são, de certo modo, responsáveis não só pela sua formação, como também pela manutenção de seus objetivos finais e pelas suas preferências. É isso que o uso dos bens primários pressupõe. Mesmo se o indivíduo tiver preferências, digamos, extravagantes, ele é responsável por suas escolhas e predileções; com isso, não se pode considerar tais sujeitos como passíveis de seus desejos, mas cidadãos cujas escolhas são parte de uma formação moral” (JORDÃO, 2012, p. 152).

16، $\mathrm{O}$ argumento a favor dos dois princípios da justiça não supõe que as partes têm objetivos particulares, mas apenas que elas desejam certos bens primários. São coisas que é racional desejar, independentemente de outros desejos. Assim, dada a natureza humana, desejá-las faz parte de ser racional; e embora se presuma que cada um tenha alguma concepção da felicidade, nada se sabe sobre os objetivos finais de cada um. A preferência por bens primários é derivada, portanto, apenas das suposições mais gerais sobre a racionalidade e sobre as condições da vida humana. Agir com base nos princípios da justiça é agir com base em imperativos categóricos, no sentido de que eles se aplicam a nós, quaisquer que sejam os nossos objetivos particulares. Isso simplesmente reflete o fato de que nenhuma dessas contingências aparece como premissa em sua dedução" (RAWLS, 2002, p.277-8). 


\section{Referências Bibliográficas:}

AUDARD, Catherine. Introdução: John Rawls e o conceito do político. In: RAWLS, John. Justiça e democracia. Tradução por Irene A. Paternot. São Paulo: Martins Fontes, 2000, p. XIII-XXXVII. (Coleção Justiça e Direito).

BRAGA, A. F. S. Kant, Rawls e o utilitarismo: justiça e bem na filosofia contemporânea. Rio de Janeiro, Contraponto, 2011.

BROWNE, D. E .,“The Contract Theory of Justice,’Philosophical Papers 5 (1976):1-10.

BRUDNEY, Daniel, Hypothetical Consent and Moral Force, Law and Philosophy. 10 (1991):235-70.

BENTHAN, Jeremy, 1748, Uma Introdução aos Princípios da Moral e da Legislação/Jeremy Bentran: tradução LuizJoão Baraúna. Nova Cultural.1989.

BEITZ, C. Rawls's Law of Peoples. Ethics, Vol.4, Nº110, 1999.

BOEIRA, Nelson. Sobre a deliberação em questões públicas. In Nythamar Fernandes de Oliveira e Draiton Gonzaga de Souza. Justiça e Política. Homenagem a Otfried Hoffe. Porto Alegre: EDIPUCRS, 2003.

CARE, Norman, S., Contractualism and Moral Criticism, Review of Metaphysics 23(1969):85-101.

DIETERLEN, Paulette, "La filosofía política de John Rawls", Revista Mexicana de Ciencias Políticas y Sociales, nueva época, año XXXVII, núm. 150, octubre-diciembre de 1992.

DANNER, Leno Francisco. O Fato do Pluralismo em Rawls: sobre a Fundamentação da Sociedade Política. Revista Estudos Filosóficosnº 5 /2010 Pág. 155 - 173.

FERRAZ, Sérgio, Modelos de Sociedades Justas: Rawls e a tradição utilitarista. Ágora filosófica, Ano 11, n. 2, jul./dez. 2011. pp. 123-157.

GUILLARME, Bertrand. Rawls et le libéralisme politique. In: Revue Française de Science Politique. Volume 46: Pluralisme, Justice, Égalité - de lémpirique au philosophique dans l'étude de la démocratie, n. 2, abr. 1996. p. 321-43.

KOLM, Serge-Christophe. Teorias modernas da justiça. Tradução Jefferson Luiz Camargo e Luís Carlos Borges. São Paulo: Martins Fontes, 2000.

KYMLICKA, Will. Multicultural Citizenship. Inglaterra: Oxford University Press, 1996;

MILLER, Richard, "Rawls, Risk, and Utilitarianism,” Philosophical Studies 8 (1975):55-61.

MILO, Ronald, Contractarian Constructivism. Journal of Philosophy 122. (1995):181-204. 
HENNIGFELD, Jochem; JANSOHN, Heinz (Org.). Filósofos da atualidade: uma introdução. São Leopoldo: Ed. UNISINOS, 2006.

JORDÃO, Marco Aurélio de Medeiros. O justo como proposta de superação. Revista Opinião Filosófica, Porto Alegre, v. 03; nº 02, 2012.

KUKATHAS, Chandran e PETTIT, Philip. Rawls, Uma Teoria da Justiça e seus críticos. Tradução por Maria Carvalho. Lisboa: Gradiva Publicações, 1990.

OLIVEIRA, Nythamar. Rawls. Rio de Janeiro: Jorge Zahar, 2003.

POGGE, Thomas. John Rawls: His Life and Theory of Justice. Oxford: Oxford University Press, 2007.

. "On Justification". In: POGGE, Thomas. John Rawls: His Life and Theory of Justice. Oxford: Oxford University Press, 2007, p. 161-177.

RAWLS, John. Uma teoria da justiça. 2. ed. São Paulo: Martins Fontes, 2002.

2000.

. O liberalismo político. Trad. Dinah de Abreu Azevedo. São Paulo: Editora Ática, . Justiça e democracia. Tradução de Irene A. Paternot. São Paulo: Martins Fontes, $2002 \mathrm{a}$.

The Sense of Justice. In: Collected Papers (Org. Samuel Freeman) CambridgeMassachussets: Harvard University Press, 1999.

RODILLA, Miguel Angel. Presentacion. In: RAWLS, John. Justicia como equidad materiales para una teoria de la justicia. Traducción Miguel Ángel Rodilla. Madrid: Editorial Tecnos, 1986 (Biblioteca Universitaria). p. IX-L.

SCARRE, Geoffrey. Utilitarianism. TedHONDERICH (ed.). Problems of Philosophy. London: Routledge, 1996.

SCANLON, Thomas. Rawls 'Theory of justice'. In: DANIELS, Norman. Reading Rawls: critical studies on Rawls' A Theory of justice. New York: Basic Books, s.d., cap. 8, pp. 169-205.

VITA, Álvaro de. A justiça igualitária e seus críticos. São Paulo: Unesp, 2002, capítulo 6, pp. 207-276.

. O liberalismo igualitário: sociedade democrática e justiça internacional.São Paulo: Martins Fontes, 2008, cap. I, pp. 21-60.

VALLESPÍN OÑA, F. Nuevas Teorías del Contrato Social: John Rawls Robert Nozick y James Buchanan, Alianza, Madrid, 1985. 
WEBER, Thadeu. Autonomia e consenso sobreposto em Rawls. Ethic@- Florianópolis, v. 10, n. 3, p. $131-153$, Dez. 2011.

ZAMBAM, Neuro José. A teoria da justiça de John Rawls: uma leitura. Passo Fundo: Ed. UPF, 2004. 